\title{
Gateways to New Learnings: Walking to Re/Vision an International Practicum
}

\author{
Christine L. Cho \\ Julie K. Corkett \\ Nipissing University
}

\begin{abstract}
:
We engage in a creative exploration of the ways in which a walk provided us with insights into how we might enhance the curriculum for a teacher education international practicum in Italy. Drawing from a currere framework, we shifted to mindful walking, and we tell our story in three parts that represent the various stages of our mindful engagement: intention; attention; and attitude. Walking in this way provided the impetus for us to re-examine the curriculum of the international practicum. We argue that mindful walking has the potential to increase observation skills and open up ways to develop deeper cultural connections in an international practicum. We consider what those connections could do to enhance the practicum and our teacher candidates' experience.
\end{abstract}

Keywords: mindful walking; international practicum; curriculum 


\section{Les Passerelles vers de nouveaux apprentissages : marcher vers la vision (de nouveau) d'un stage international}

\section{Résumé :}

Nous nous engageons dans une exploration créative de la manière dont une marche nous a permis de mieux comprendre comment nous pourrions améliorer le programme d'un stage international de formation des enseignant(e)s en Italie. En nous inspirant d'un cadre " currere ", nous sommes passés à la marche attentive et nous racontons notre histoire en trois parties qui représentent les différentes étapes de notre engagement conscient : l'intention; l'attention; et l'attitude. Marcher de cette façon nous a incité à réexaminer le programme du stage international. Nous soutenons que la marche consciente a le potentiel d'augmenter les compétences d'observation et d'ouvrir des moyens de développer des liens culturels plus profonds dans un stage international. Nous réfléchissons à ce que ces liens pourraient faire pour améliorer le stage et l'expérience de nos candidats enseignants.

Mots clés : la marche consciente; le stage international; le curriculum 


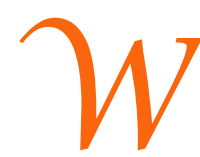

alking can serve many functions. Walking could be a deliberate act to support arriving at a given destination, or it could be an unconscious activity undertaken without expectation or agenda. Walking could also be, as Feinberg (2016) asserts, a mindful practice for generating ideas and creative insight. As university professors privileged to facilitate an international practicum in Italy for Canadian Bachelor of Education students, ${ }^{1}$ we had grown accustomed to using walking for both exercise and as our primary mode of transportation. However, through offering the practicum and growing increasingly conscious of the experience for ourselves and others, we recognized that we were engaging in Pinar's (2010) currere. We engaged in the act of looking back, considering the future and being in the moment. Currere gave us deliberate focus which led to deepened creative insight and new ways of thinking. Our experience utilizing a currere framework dovetails nicely with Goertz (2018) who, in describing a walking pedagogy, asserts that

walking can be seen as a metaphor for change and dynamism: just as the walker is on the move, not stuck to one place or perspective, so too, the student is in a particularly fluid time of life when, ideally, old patterns are broken, ideas are approached anew and self-identity undergoes transformation. (p. 57)

Thinking about walking as an act that encourages heightened awareness led us to Shapiro et al. (2006) and their discussion of mindfulness as containing three key components: intention, the purposeful and intuitive motivation for attentiveness as an end goal; attention, the necessary cognitive processes for mindfulness; and attitude, the emotional connections made through attentive focus. Ergas (2019) extends these three key components of mindfulness by asserting all three facets must be present in order for mindfulness practice to occur.

Influenced by the three aspects of currere (examining past experiences with international practicums, thinking about future offerings and staying in the moment) and guided by notions of change, transformation and mindful practice, as drawn from Goertz (2018) and Ergas (2019), we began to understand the possibilities of the international practicum differently. We did not design the curriculum for the practicum, but as facilitators we had the opportunity to suggest curriculum modifications and new directions for future trips. Some aspects were working very well, such as the partnerships with the schools and teachers. Yet, we also observed many of our students staying in the hotel during their free time, not venturing out into the community and choosing to eat at familiar fast-food chains. We wondered how we might keep the best of what was working and further enrich the experience, enticing our students to interact more with the community.

\footnotetext{
${ }^{1}$ Our university requires teacher candidates to complete a CLE: Community Leadership Experience (previously referred to as an alternative practicum). A variety of locations are offered every year. The Italy experience was three weeks in duration and cost around $\$ 4300$. Students stayed in four-star hotels in Treviso, Sulmona and Rome. Most of the time was spent in Sulmona with the opportunity to teach (in English) students in various partner schools: nursery schools, elementary schools, high schools and an adult continuing education program. Interested students, at a specified point in their program, could apply for an international practicum. Logistics determined the cap on the number of teacher candidates who could attend (i.e., airline and hotel availability). Teacher candidates completed an application which included reference letters and a motivation questionnaire. A panel of faculty members made the final decision regarding who could attend (which included GPA considerations and success on previous practicums). Almost without exception, any teacher candidate expressing interest could participate.
} 
The international practicum runs for three weeks, with the first few days in Treviso, just north of Venice, and the final few days in Rome. The rest of the time, teacher candidates are placed in schools in the city of Sulmona. The old part of Sulmona, where we stayed, dates back to 304 BCE (Visit Sulmona, 2015) and has remnants of an ancient Roman viaduct, and cobblestone roads, with many of the medieval buildings still standing. The old city is surrounded by a larger, more sprawling modern municipality. Sulmona, therefore, has two distinct personalities. At the centre, the medieval part is small and retains the feel of a medieval Roman town. The newer, larger, outlying municipality is more urban. While Sulmona is considered a city, as we describe Sulmona, we tend to use the word town for the medieval part and city for the newer municipality.

As we became more attuned to our surroundings, the sights and sounds and smells of the quaint, old part of Sulmona enhanced our understanding of what might be central in an international practicum, but which had not yet been, to our mind, thoughtfully included: meaningful connection with, and immersion in, the Italian culture. Just being in a location is not a commitment to immersion. It was our perception that something pivotal was missing in the Italian practicum curriculum design and it was through our mindful walk that we were able to examine and understand what the missing element might be. We considered the components of intention, attention and attitude, as we consciously engaged a walking practice to assist in our pedagogical development.

Our experience of attuning through walking opened up a pedagogical shift for us. We invite others to walk beside us as we revisit, through images and narrative, the journey that helped us break our physical and mental patterns in order to think differently about location and place. Through this shift, we entered a space in which we could envision ways to enhance the experience of the international practicum in Italy.

\section{Entering into Spaces: The Gates of Sulmona}

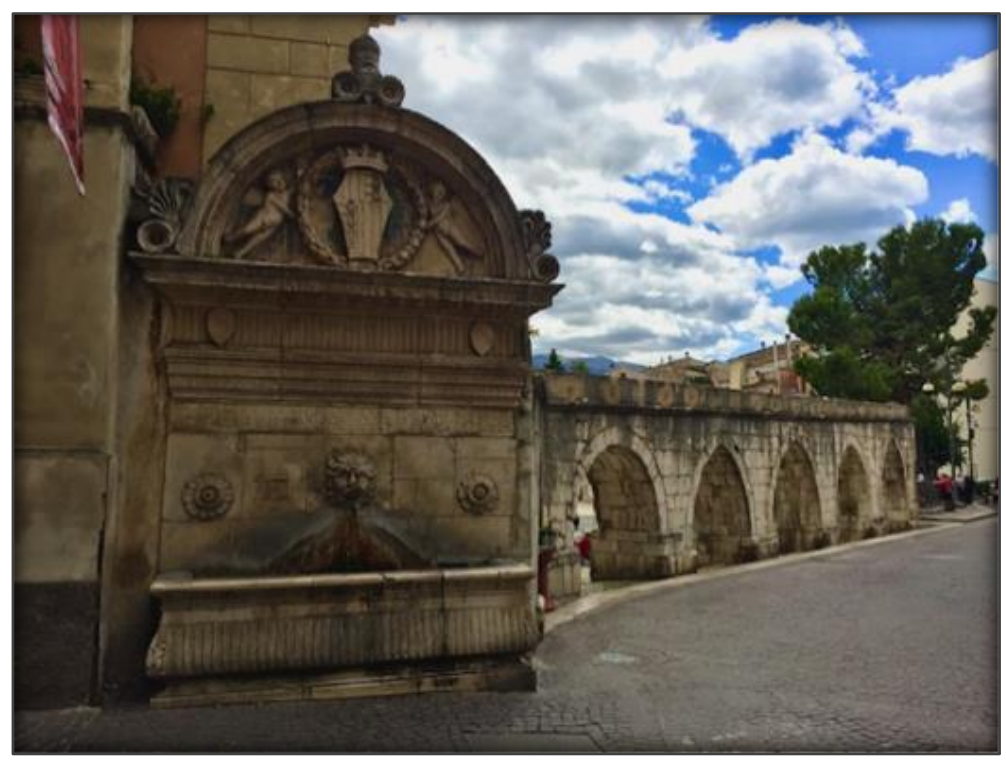

Fonte del Vecchio. Photo credit: Julie Corkett. Used with permission. 
It was May 2017, the tenth year our university had offered an alternative practicum for our Bachelor of Education students in Sulmona, Italy. Sulmona has a breathtakingly beautiful ancient component, rich with history and known for being the birthplace of the poet Ovid (born $43 \mathrm{BCE}$ ). Surrounded by the Apennine mountains, Sulmona is nestled in the Peligna Valley. A piece of the Roman aqueduct (1256 CE) is still visible in the town square, the Piazza Garibaldi. In the piazza, the Fonte del Vecchio (Fountain of the Old, 1474 CE) still offers a cool drink of water. The town was fortified in the 1300's with a medieval wall system (Welcome to Sulmona, 2015). Much of the wall and ten of its gates are still standing or mostly recognizable. Our walk began with a quest to find the gates.

Intention: Discovering Our End Goal

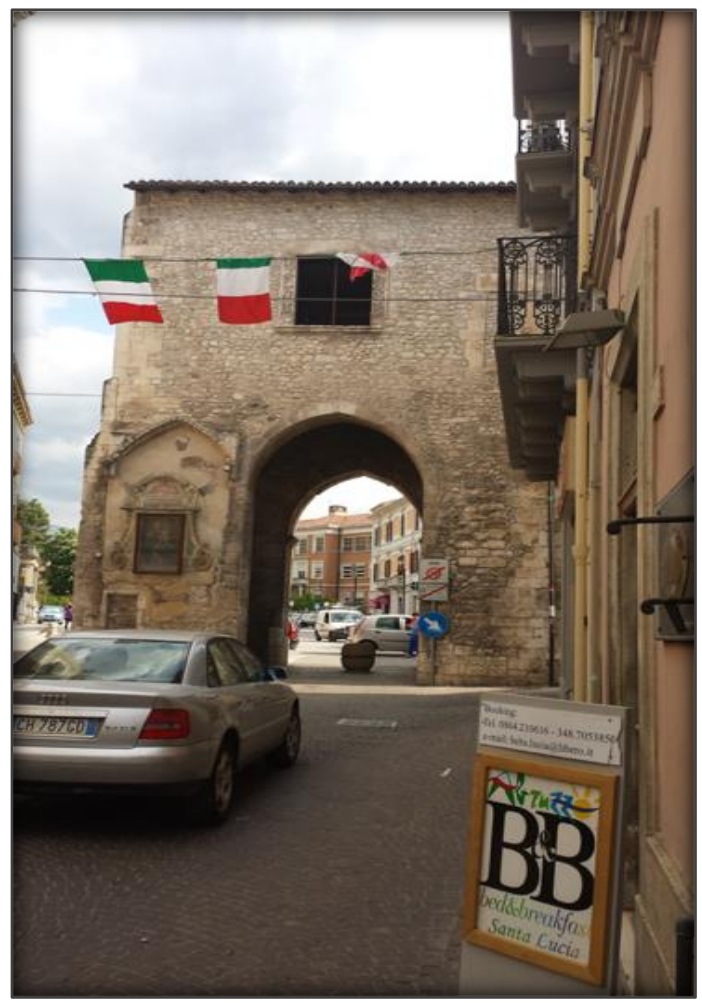

Porta Napoli. Photo credit: Christine Cho. Used with permission.

Our mindful walk did not begin as such. Rather, we took a brisk walk to where we thought the Porta Napoli gate was located. We walked with the aim of just trying to get to the gate. We were not conscious of place because we were so focused on getting to our destination. We stood at a busy intersection with an obstruction in the centre, an archway that separated the ancient, medieval town and the modern city. The archway marked the end of a one-way street and the place where traffic flowed in both directions. We had not been attending to the significance of the archway. It had seemed like an interesting bit of prominent architecture with some history unknown to us. We were shocked when we realized that this structure was the original south entrance to the town. We felt rather naïve. We had found the Porta Napoli, which we realized was something we had already 
encountered many times before, visiting our teacher candidates at two of our partner schools. We had not attended to the significance of the archway until that moment. What unfolds is how this socalled finding was evidence of our inattentiveness and our own awakening. Indeed, we had a bit of an epiphany. What were we doing? Why were we rushing? We realized we had just been going through the motions of traversing the town and executing our mission. Our cadence was matching our agitated emotions. We were in an unchecked state, marching to our destinations, not experiencing the journey. We started to wonder, if we were walking in an unreflective manner, how were our students walking through the town? How were they experiencing their placement? In what ways might the structure of the practicum be impeding, as opposed to enhancing, their experience? How could we model for them ways to slow down - to be in the moment, absorbing and reflecting on Sulmona's culture and rich history, and the ways in which the town and education system has been reshaped over time?

We were conscious of the potential of learning with/in Italy, a country with deep roots to education that reach back to antiquity. When we walked to and from our partner schools, we were engaging in the first phase of Pinar's (2010) currere, looking back. We shared stories of past international practicums; we considered our perceptions of the strengths and weaknesses of the experience and found resonance with what Barrett and Fry (2005) maintain is the telling and hearing of stories as a catalyst for change. Reflecting on these stories, we realized that although an underlying cohesive thread of the practicum's curriculum was a connection to the culture of the locations in which we were situated, we, ourselves, had not connected this to a teleological motivation for attentiveness. What was our purpose in bringing students to Italy? What did we hope to achieve and how might becoming more attuned with our surroundings assist us in recognizing that deeper purpose?

The shock of recognizing the first gate as something we had previously dismissed gave us the wherewithal to slow down and examine a deeper, more fundamental question regarding the structure of the Italian practicum. What was missing? What opportunities and experiences were being overlooked? We decided to begin again, with intention, to listen to the sounds of the town, reexamining how we were looking at things and, in doing so, become more attuned to our internal feelings and external sensations. On the surface, our motivation and intention were to find the ten gates, but that goal was lacking the key components of mindful attentiveness and attunement. Our recognition that we needed to engage with place differently also provided parallel insights into the organization and intent of the practicum that we needed to explore further. We proceeded, henceforth, with attention.

\section{Attention: Recognizing the Cognitive Process Necessary for Mindfulness}

Having set our intentions to be purposeful and consciously attentive in order to reconsider the practicum curriculum, we made a decision. As we had already well-traversed through the internal part of old Sulmona on a daily basis, we now considered what it might have been like to approach it as a visitor from outside the old city walls. Approaching the gate from inside the town, there was an 
almost palpable energy that seemed to direct people away from the gate. We never saw anyone going through the gate. Standing there, with a new appreciation for the structure as a passageway, we perceived nonetheless, an unsaid, unwritten prohibition: "Do not pass!" Maybe that is why we had not gone through the Porta Napoli; to do so would be leaving the ancient part of Sulmona. By walking around the gate, we were, somehow, not leaving but connecting the old town with the new city. Drawing on our connection with the energy emanating from our surroundings, we had renewed determination to slow down and allow ourselves to experience with all our senses. Were we subconsciously avoiding the exit? What if we reframed our perspective to look for entry points? In what ways were we looking for new entry points to guide our students in connecting with the community? We reasoned the best way to find the gates was to circumvent the town which paralleled our shift in perspective to examine the practicum from an outsider's perspective, to take a step back and examine the curriculum more holistically. We put away our map of the town and gave conscious thought to our senses as our guide for locating the gates from outside, rather than inside the town's walls. We drew connections with this act as metaphorically reflecting our visitor status in Sulmona as well as opening ourselves up to new curricular insights and possibilities.

Imagining ourselves approaching the fortified town as a traveller gave us a new perspective. We began paying attention to the architecture and the roads. Could a contemporary busy road be an extension of an original entry point? Could a space we had not noticed before have been an entry way to ancient Sulmona, perhaps a less fortified gate that had not withstood the degradation of time or the ravages of the 1706 earthquake? What, 700 years ago, would we have sensed as we travelled to the gates of this town? What would we have heard? Seen? Smelled? Once we changed our perspective, the gates became a little more obvious and we entered into a new space, attuning to our hearts and minds. Even the cobblestone under our feet took on new significance. We considered how the grooves worn deep in the stones were paths forged over the centuries. How we traversed these pathways was changing. 


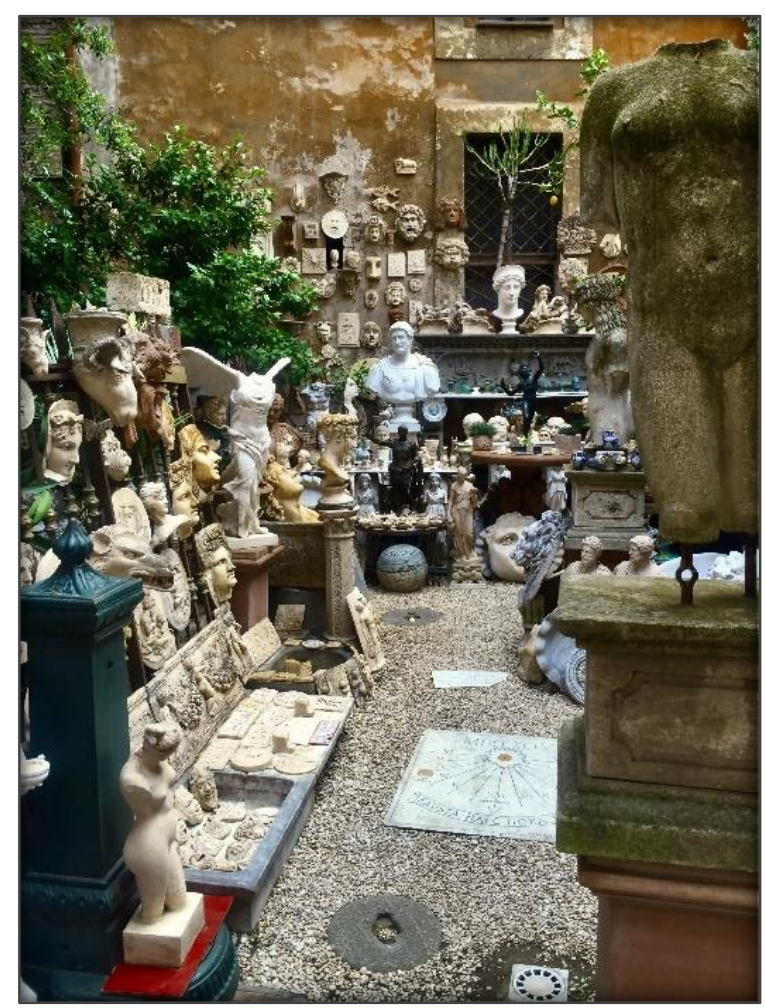

An Italian Market. Photo credit: Julie Corkett. Used with permission.

Our focus on being attentive made us recall an Italian market we had previously visited outside of Sulmona. As we recalled the small sculptures and ornaments, the plethora of options, we began to consider the bounty that exists in terms of the potential of a practicum. The image represents multiple realities and the complex cultural impact at play in an international practicum. For us, the market symbolizes the complexity of integrating ourselves and our teacher candidates into another culture. The market served to remind us to engage our senses as we journeyed to find the Porta Japasseri gate.

Some of the gates show the ravages of time and the impact of an earthquake in 1706 . The Porta Japasseri, the oldest gate in Sulmona, is one example. If we had not attuned to our surroundings, we would not have known the gate was there at all. The gate was so badly damaged it is almost non-existent. While much of the ancient wall was still intact, all that was left of this gate was its crumbling stone piers. Carefully studying the architecture, looking for clues in the stones and the direction of the streets, we were able to pay closer attention to things we might have otherwise disregarded, such this deteriorated gate. We had to imagine what the gate might have looked like and, in doing so, transferred this kind of imagining to a reconceptualization of the international practicum 


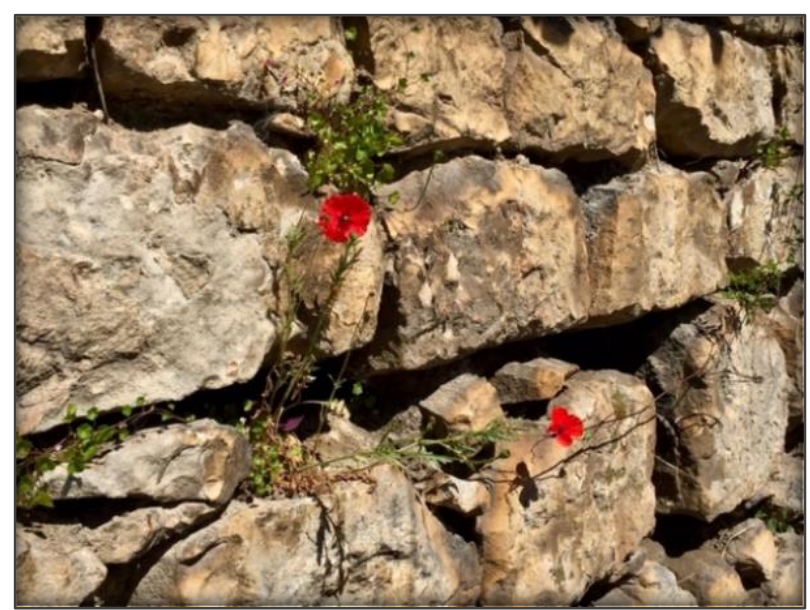

Tenacious Poppies, Porta Japasseri. Photo credit: Julie Corkett. Used with permission.

The tenacious poppies, emerging from the ancient wall of stones by the Porta Japasseri enriched our literal and metaphorical journey. We recognized that the poppies had enough sustenance to grow but wondered what they might become under better conditions. What could enhance their growth? What was enhancing our growth? We began to consider ways that the design of the practicum could get teacher candidates to attune to their surroundings in a way that would transfer to and enhance their teaching practices. We thought about the Harvard Medical School study in which future doctors took part in a series of eight art observation exercises in combination with classes on physical diagnosis (Naghshineh et al., 2008). Attending to the artworks in a focused and concentrated manner led to an increase in the medical students' ability to make detailed observations of artworks and heightened their physical examination skills. In a similar spirit, we argue that mindful walking has the potential to increase teacher candidates' observation skills of both their environment and their recognition of the role culture plays in the classroom.

One area of curricular growth that we wanted to address was getting teacher candidates to engage fully with the culture and community of Sulmona. We observed the majority of teacher candidates had formed a Canadian Island: eating together in the hotel rather than in the community; sticking to the same beaten path on their way to and from school; and being critical of the Italian school system in relation to Ontario schools. We wanted the structure of the international practicum to reflect the exploration of and participation in the Italian culture. We feel it is not sufficient to be in another country to lay claim to global exposure, a sentiment we found our teacher candidates expressing; we feel it is imperative to become mindful of being part of a complex cultural system. We need to hear, see, taste, smell and listen to all of the socio-cultural aspects, not from a distance, but as active participants.

\section{Attitude: Making Emotional Connections}

A key aspect of walking with mindfulness is attitude, which is the emotional connection made through attentive focus, or, to draw from Pinar's (2010) currere, being in the moment. As we looked carefully for the gates, we reminded ourselves of what we call "doing the bee". Bees are excellent 
navigators (Menzel et al., 2005), and they employ a strategy of looking back when they leave the hive. As they fly, they turn around to see where they have come from. As we know, things look different when you are coming from another direction. Looking back helps the bees keep their bearings. We attempted to do the same thing, both literally, as we worked from outside the town to find the ingresses, and figuratively, as we considered the practicum experience. That is, in order to move forward in our facilitating, and embracing the tenets of currere, we were looking back, considering the future but most importantly in terms of attitude, we were being in the moment. We actively looked back (on student coursework and the entirety of the practicum experiences) to tease apart what worked and what could be refined as we considered ways to move teacher candidates forward in attuning to Italian culture. We had developed a new attitude-one supported by mindfulness.

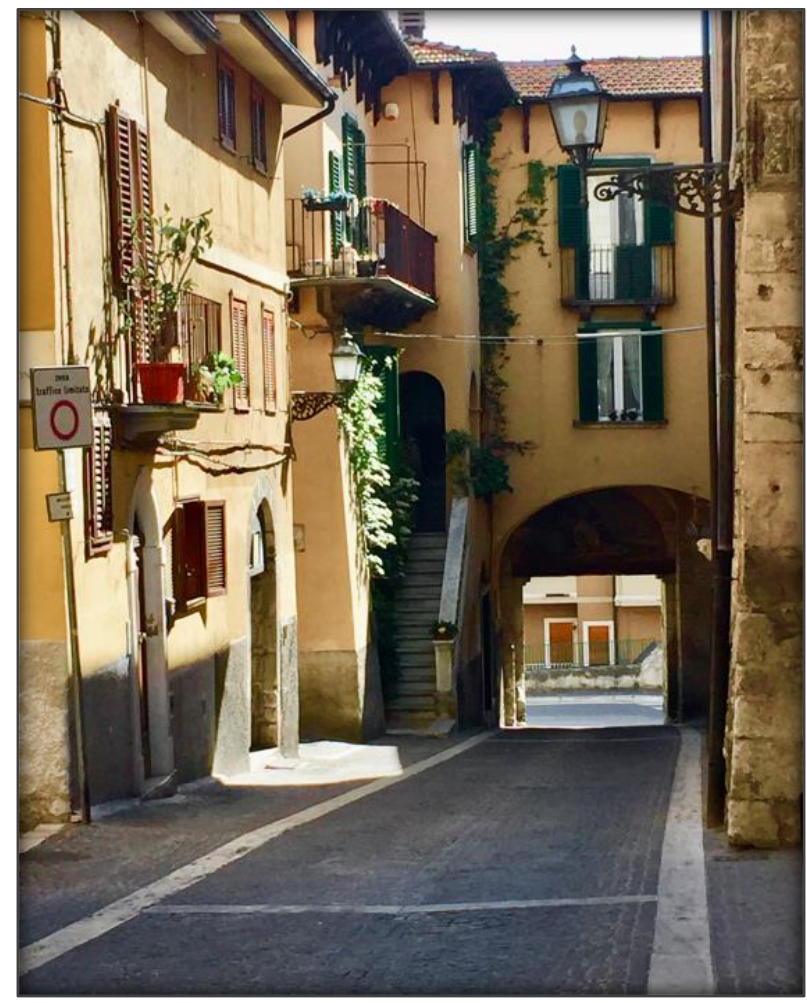

Porta Santa Maria della Tomba. Photo credit: Julie Corkett. Used with permission.

Adjusting our attitude to navigate like bees helped us find the Porta Santa Maria della Tomba. Once again, we previously thought this was just a nice archway into the newer part of the city. As we walked toward the gate, we became attuned to what had been hidden from us during previous unattentive walks. We listened to the sounds and smells of people preparing their lunch: clinking of cutlery; a tap running; the snippet of a conversation. While Porta Santa Maria della Tomba is the most recent of the gates (built in the $15^{\text {th }}-16^{\text {th }}$ century), the doors are no longer intact, and a house has been built over the original archway of the gate. We began to recognize how the old was absorbed and repurposed into the new. The surrounding buildings have been stuccoed and painted in a coordinating yellow ochre. In the image, the cobblestone road is still visible, albeit with some 
modern refinements. Porta Santa Maria della Tomba represents a beautiful blend of keeping the old while developing a new purpose. This mirrored our thoughts as we thought deeply about how to keep the best of what was working in the practicum curriculum, while building on new layers and new opportunities that would support teacher candidate development through international experience.

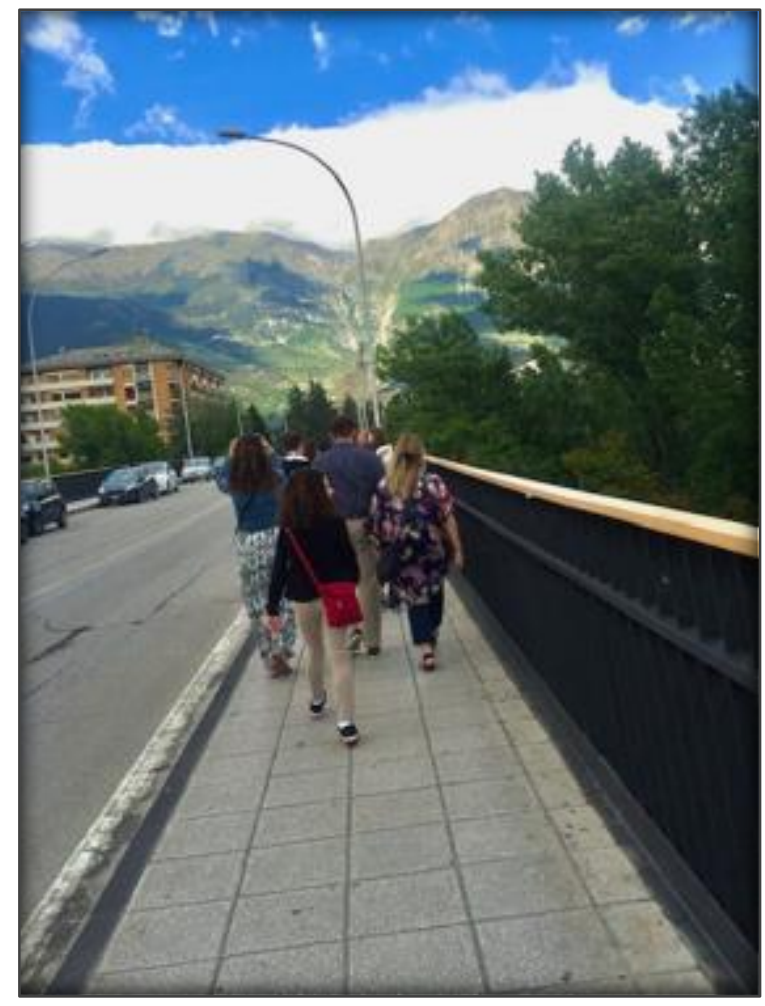

Walking to School. Photo credit: Julie Corkett. Used with permission.

We were changed by our mindful exploration. Attending to the history of the gates of Sulmona, attuning to our senses, and closely examining the architecture in front of us, we gained a deeper understanding of where we were living, and what we had been taken for granted. We were able to explicitly identify our desire for teacher candidates to be more than physically present in an unfamiliar community. We want them to get more than a glimpse of the life of the teachers and students of Sulmona. By strengthening their connection to the Italian culture and the community, teacher candidates might begin to question how they are interpreting what is occurring in schools, both abroad and at home.

We considered what we could do to facilitate our teacher candidates' stronger connection with Sulmona's culture, and we decided to share our walk with our teacher candidates. During an evening debrief, we told the teacher candidates about our quest to find the gates and the impact it had on us. We provided the teacher candidates with an activity that we designed for the purpose of encouraging the teacher candidates to connect more deeply with the community and its culture. Three students told us that, inspired by the activity and our story, they ventured off the beaten track and found a lovely restaurant in which they savoured quintessential Abruzzo dishes. They lingered 
over their meal, took their time with each course, spoiling themselves and soaking up the atmosphere. They offered vivid descriptions of the garden, including the smells and tastes of the food.

We realized our teacher candidates needed a greater introduction to the Italian school system before leaving Canada and we decided to incorporate that change into the practicum design. We also decided to task future practicum participants with researching different aspects of the area before their arrival and with sharing that information with their colleagues in creative ways. Another change we decided to implement was how we introduce our students to the town. Normally, one of the first things we do when arriving in our practicum location is to conduct a walking tour of the general vicinity, followed the next day by a walk to all the partner schools. To encourage mindfulness in our teacher candidates, we no longer wish to march to our destination; rather, we want to encourage them (and ourselves) to attend to their senses as they traverse the paths. We intend to be attentive, and this shift in attitude will encourage students to take different routes to and from school, embracing a discovery mindset, which could facilitate the background research our teacher candidates are asked to prepare in advance. Walking with purposeful destination fosters the navigational and observational skills that are transferrable to our ways of teaching and being.

\section{Conclusion}

What began as an excursion to find the ten gates of Sulmona grew into a mindful walk that brought together our past experiences and future aspirations with a desire to be in the moment and attuned to our surroundings. Our intention, finding curricular understandings of the ways we could connect on a sensory level with the culture and education system in Sulmona came about because we implemented attention to our mindfulness and our attentive focus aided us in making emotional connections. Our pedagogical shift positively impacted our vision of the international practicum and exposed the ways in which we could marinate in the experience. In attuning, we enhanced our teaching praxis as we wandered and wondered what else is possible.

Learning to walk with mindfulness and attunement allowed us to examine the role culture plays in the curriculum of an international practicum. We recognize mindful walking in community as a form of pedagogy that we want to encourage in our teacher candidates and, by extension, their future work in schools. Our biggest learning outcome from our gate walk was that careful, mindful attention, combined with purpose and emotional connection, is a pathway to cultural immersion. As we get better at mindful walking and share the practice with future teacher candidates on an international practicum, we will work to make those community and cultural connections stronger and more meaningful.

\section{About the Authors}

Christine L. Cho, PhD, is an associate professor at Nipissing University's Schulich School of Education. A practicing visual artist and a former elementary school teacher, Christine utilizes visual media and critical pedagogy in the courses she offers on curriculum design and on diversity and 
inclusion. Christine also facilitates international excursions for teacher candidates to expand their concepts of schooling.

Julie K. Corkett, PhD, is a tenured associate professor at the Schulich School of Education at Nipissing University. Dr. Corkett's research interests pertain to special education, educational psychology, teacher education, pedagogy and technology. She has published several peer-reviewed articles and book chapters pertaining to these topics, has presented her research at numerous international and national conferences, and has been an invited guest lecturer both nationally and internationally. Over the past 12 years, Julie has facilitated international excursions in Kenya, China, Ecuador, Nicaragua, Italy and France.

\section{References}

Barrett, F. J., \& Fry, R. E. (2005). Appreciative inquiry: A positive approach to building cooperative capacity. Taos Institute.

Ergas, O. (2019). Mindfulness in, as and of education: Three roles of mindfulness in education. Journal of Philosophy of Education, 53(2), 340-358. https://doi.org/10.1111/1467-9752.12349

Feinberg, P. P. (2016). Towards a walking-based pedagogy. Journal of the Canadian Association for Curriculum Studies, 14(1), 147-165. https://jcacs.journals.yorku.ca/index.php/jcacs/article /download/40312/36186

Goertz , K. K. (2017). Walking as pedagogy: Integrating intentional walking in the college curriculum. In M. C. Hall, Y. Ram, \& N. Shoval (Eds.), The Routledge International Handbook of Walking (pp. 55-64). Routledge. https://www.researchgate.net/publication/324486130_Walking_ as_Pedagogy

Menzel, R., Greggers, U., Smith, A., Berger, S., Brandt, R., Brunke, S., Bundrock, G., Hülse, S., Plümpe, T., Schaupp, F., Schüttler, E ., Stach, S., Stindt, J., Stollhoff, N., \& Watzl, S. (2005). Honey bees navigate according to a map-like spatial memory. Proceedings of the National Academy of Sciences, 102(8), 3040-3045. https://doi.org/10.1073/pnas.0408550102

Naghshineh, S., Hafler, J. P., Miller, A. R., Blanco, M. A., Lipsitz, S. R. Dubroff, R. P., Khoshbin, S., \& Katz, J. T. (2008). Formal art observation training improves medical students' visual diagnostic skills. Journal of General Internal Medicine, 23(7), pp. 991-997. https://doi.org/10.1007/s11606-0080667-0

Pinar, W. F. (2010) Notes on a blue guitar. Journal of Educational Controversy, 5(1), 1-9. https://cedar. wwu.edu/jec/vol5/iss1/18

Shapiro, S. L., Carlson, L. E., Astin, J. A., \& Freedman, B. (2006). Mechanisms of mindfulness. Journal of Clinical Psychology, 62(3), 373-386. 10,1002/jclp.20237

Visit Sulmona. (2015). What to see-fortifications [Online brochure]. Visit Sulmona. http://www.visitsulmona.it/poi/84/porta-japasseri/9\#sthash.eBo9jXso.3g3hvDfL.dpbs

Welcome to Sulmona. (2015). The ancient gates of Sulmona-A circular walking [Online brochure]. Welcome to Sulmona. Tour. https://welcometosulmona.com/wp-content/uploads/2015 /09/AncientGatesDownload.pdf 